\title{
Arteriovenous loops in microsurgical free tissue transfer in reconstruction of central sternal defects
}

\author{
Matthias A. Reichenberger, MD, Patrick S. Harenberg, MD, Michael Pelzer, MD, Emre Gazyakan, MD, \\ Henning Ryssel, MD, Günter Germann, MD, PhD, and Holger Engel, MD
}

\begin{abstract}
Objective: In some patients with chest wall defects, free tissue transfer is indicated. Complications arise if multiple operations have left the trunk devoid of recipient vessels. In such patients, an arteriovenous loop between the cepahlic vein and the thoracoacromial artery can be used.
\end{abstract}

\begin{abstract}
Methods: A review of all our patients who underwent chest wall reconstruction with a cephalic vein-thoracoacromial artery loop between 2000 and 2009 was performed $(n=29,19$ women and 10 men). The mean age was 64.9 years. Underlying causes were sternal osteomyelitis $(n=20)$, tumor $(n=4)$, and osteoradionecrosis $(n=5)$. All patients were in American Society of Anesthesiologists classes III and IV. Flap selection, intraoperative and postoperative complications, operative time, time of ventilatory support, mean hospital stay, and midterm survival were recorded.
\end{abstract}
Results: Twenty-five patients received a tensor fascia lata flap, 2 a vertical rectus myocutaneuos flap, and 2 a deep inferior epigastric perforator flap. Mean duration of surgery was 6.8 hours (4.7-10.5 hours). Two transplanted tissue flaps died and/or had to be removed and 4 were revised successfully. Seven patients had wound complications such as infection or prolonged wound healing. Mean time for ventilator support was 93.6 hours (4-463 hours). The median intensive care unit time was 11 days and the overall hospital stay 27.4 days (11-102 days). One-year survival in the whole group was $69.8 \%$.

Conclusions: The concept of arteriovenous loops allows creation of neovessels at the recipient site and has proven to be a superb tool to facilitate free tissue transfer or to provide an exit strategy in situations with unexpected vascular problems at the recipient site. (J Thorac Cardiovasc Surg 2010;140:1283-7)

The predisposing risk factors for sternal wound infection have been widely delineated. Inasmuch as more and more interventions are performed nonsurgically by cardiologists, the patients who undergo surgery are increasingly sicker, older, and show more comorbidities than a decade ago.

This patient population requires an adjustment of the plastic surgical approach and, in selected high-risk cases, new techniques to optimize outcomes. ${ }^{1-3}$ Central chest wall defects require radical debridement before any reconstructive attempt. Local and regional muscle or musculocutaneus flaps, such as latissimus dorsi and pectoralis major flap, are generally the first choice to provide coverage of the chest wall, and multiple donor sites are usually available. ${ }^{1-7}$ However, if local/regional options may already have been used or damaged by previous operations, or the defect may be of inadequate size to be reconstructed with these options,

\footnotetext{
From the Department of Hand, Plastic, and Reconstructive Surgery, Burn Center, BG Trauma Center Ludwigshafen, Plastic and Hand Surgery, University of Heidelberg, Ludwigshafen, Germany.

Disclosures: None.

Received for publication Jan 30, 2010; revisions received April 26, 2010; accepted for publication May 16, 2010; available ahead of print June 21, 2010.

Address for reprints: Patrick S. Harenberg, MD, Department of Plastic and Hand Surgery, Burn Center, BG Trauma Center, Ludwigshafen, Department of Plastic and Hand Surgery, University of Heidelberg, Ludwig-Guttmann Str 13, 67071 Ludwigshafen, Germany (E-mail: psh11@duke.edu).

$0022-5223 / \$ 36.00$

Copyright $(c) 2010$ by The American Association for Thoracic Surgery doi:10.1016/j.jtcvs.2010.05.019
}

free tissue transfer is indicated. ${ }^{8-10}$ Unfortunately, in a small subgroup of patients, multiple operations have left the trunk devoid of recipient vessels such as the internal thoracic or the thoracodorsal vessels.

We have successfully established a new concept for microsurgical reconstruction - an arteriovenous loop between the cepahlic vein and the thoracoacromial artery to create new reliable recipient vessels. This article describes our experience with the method as a "proof of concept."

\section{PATIENTS AND CLINICAL METHODS}

This patient population comprised 29 seriously ill patients in the period from 2000 to 2008. Underlying diseases were sternal osteomyelitis $(n=20)$, tumor $(n=4)$, and osteoradionecrosis $(n=5)$. All patients had undergone one or more previous interventions related to the sternal defect (Figure 1). There were 19 women and 10 men with a mean age of 64.9 years. All patients were classified in American Society of Anesthesiologists (ASA) classes III and IV. After central full-thickness chest wall resection, all patients required free flap reconstruction. The expected extension and location of the defect were evaluated preoperatively with computed tomography. Twentyfive patients received a tensor fascia lata (TFL) flap, 2 patients a vertical rectus myocutaneuos flap, and 2 a deep inferior epigastric perforator flap. Recipient vessels were created with a temporary arteriovenous (AV) loop between the cephalic vein and the thoracoacromial artery (CTA loop) (Figure 2). Flap selection, intraoperative and postoperative complications, operative time, time of ventilatory support, mean hospital stay, and midterm survival were recorded (Tables 1 and 2).

Postoperative extubation was performed according to conventional guidelines. Eight patients required a tracheostomy owing to prolonged ventilator support. 


\section{Abbreviations and Acronyms \\ ASA $=$ American Society of Anesthesiologists \\ $\mathrm{AV}=$ arteriovenous \\ CTA $=$ arteriovenous loop between the cephalic \\ loop vein and the thoracoacromial artery \\ $\mathrm{TFL}=$ tensor fascia lata}

\section{Operative Procedure}

Radical debridement of soft tissue and bone was performed in all the cases, and resection included partial or complete resection of the sternum and removal of osteochondral sections of the ribs if indicated (Figure 3). In cases in which structural support was necessary to prevent chest wall collapse, synthetic mesh was used. ${ }^{11}$ So that the operating time could be minimized, harvesting of the flap and AV loop creation were performed simultaneously by 2 teams. For creation of the AV loop, the cephalic vein was dissected in the calculated length from the deltopectoral groove to the mid third of the upper arm. After distal division, the vein was flipped over, leaving the cephalic drainage into the subclavian vein intact.

The thoracoacromial pedicle was identified on the undersurface of the pectoralis major muscle, and the artery was prepared for AV anastomosis. After clamp removal, the loop was left open to ensure adequate perfusion until flap harvest was completed (Figure 2).

\section{Data Collection and Statistics}

Data were gathered by reviewing the medical records of 29 patients.

Descriptive statistics were calculated with SPSS version 15 (SPSS, Inc, Chicago, Ill).

We abstained from further statistical testing because the study was retrospective with a relatively low number of cases and because patients could not be grouped in statistically meaningful groups.

\section{RESULTS}

One-year survival in the whole group was $69.8 \%$. Eight patients died during a 6-month follow-up period; their deaths were not related to the reconstructive procedure.

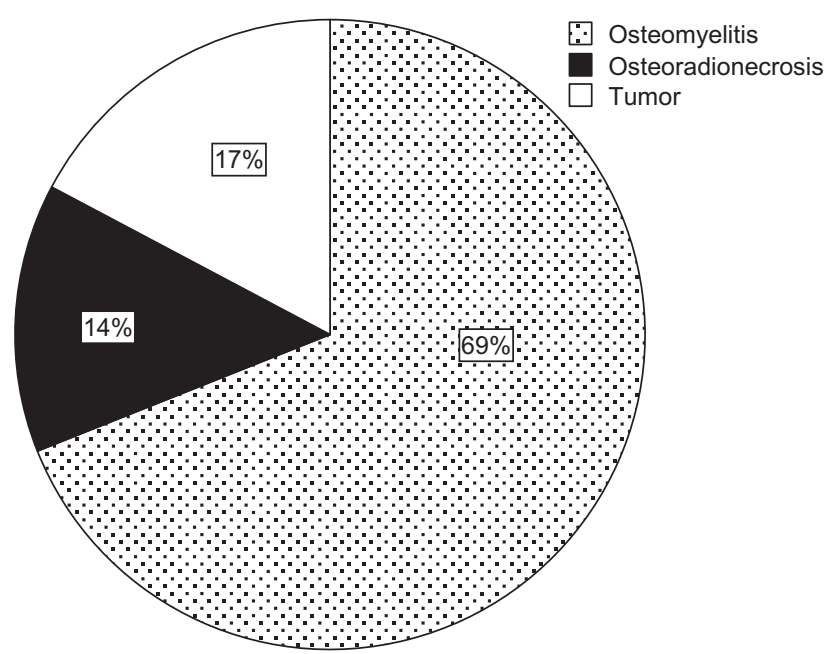

FIGURE 1. Graphic representation of the distribution of the causes of the treated sternal defects.

Only 2 transplanted tissue flaps died and/or had to be removed and 4 were revised successfully for thrombosis of the arterial $(n=2)$ or venous $(n=2)$ anastomosis. Seven patients had wound complications such as infection or prolonged wound healing. Three of them demonstrated a small area of
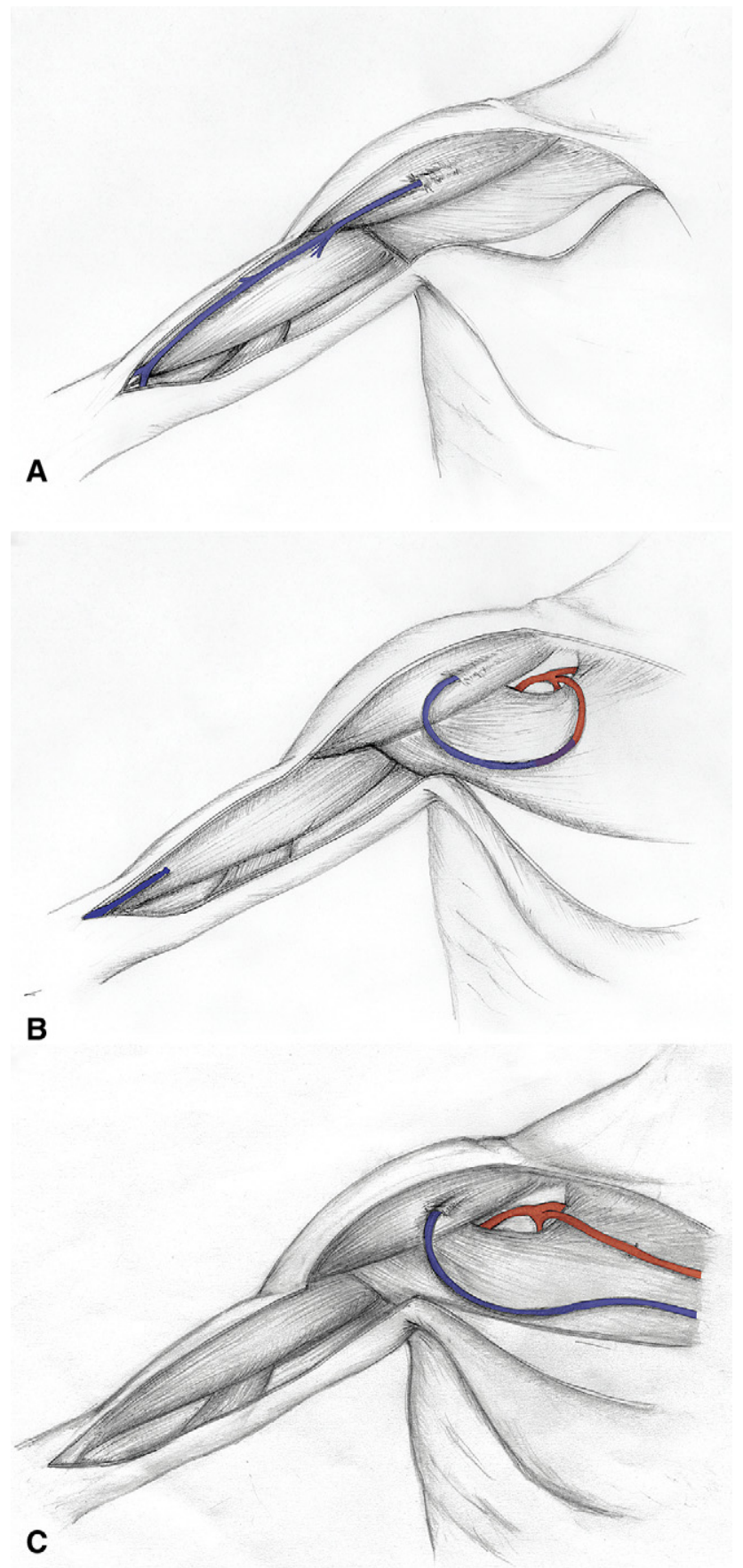

FIGURE 2. Graphic illustrations of the intraoperative situs showing the creation of the CTA loop with the dissected cepalic vein (A) and the temporary loop to the thoracoacromial artery (B) and the flap anastomosed to the divided loop (C). CTA loop, arteriovenous loop between the cephalic vein and the thoracoacromial artery. 
TABLE 1. Time on ventilator support, operating room time, hospital stay, and intensive care unit time

\begin{tabular}{lrrrrrrr}
\hline & Mean & Median & SD & 25th quartile & 75th quartile & Minimum & Maximum \\
\hline Ventilator support (h) & 197.6 & 133.0 & 207.9 & 18.5 & 351.5 & 7.3 & 0 \\
OR time (h) & 6.9 & 6.8 & 1.7 & 5.7 & 7.0 & 4.5 & 10.5 \\
ICU stay (d) & 12.4 & 11.0 & 7.8 & 13.0 & 6.0 & 56.0 \\
Hospital stay (d) & 43.0 & 29.0 & 36.0 & 10.0 & 59.5 & 9.0 & 135.0 \\
\hline
\end{tabular}

$S D$, Standard deviation; $O R$, operating room; $I C U$, intensive care unit.

necrosis at the distal part of the flap. The necrotic tips of the flaps were excised and closed secondarily. Flap donor site was revised in 2 patients who received a TFL flap (Figure 4).

\section{DISCUSSION}

Inasmuch as the success of free tissue transfers has significantly improved over the years and has reached a level sometimes superior to that of locoregional flaps, indications have been expanded toward more complex clinical situations: elderly and critically ill patients. In this patient population, vascular conditions are frequently insufficient owing to arterial occlusive diseases, diabetes, previous operations, or use of potential recipient vessels for other purposes, as in cardiac surgery. Not uncommonly, patients with sternal defects have undergone several operations, leaving the sternal chest region devoid of locoregional flaps or recipient vessels appropriate for microvacular reconstruction. In our study, all patients included in the review had undergone several operations with failure of locoregional flaps and a lack of recipient vessels. All our patients had large sternal defects. Sixteen of our 29 patients were referred to us by other hospitals after having previously received a pectoralis flap that failed owing to wound infection or (partial) flap necrosis, leaving no sufficient local/locoregional flaps to cover the defect. In all other cases, the defects were deemed too large or too deep for reconstruction with a local/locoregional flap.

All patients were classified in ASA classes III or IV owing to previously unsuccessful operations or the underlying diseases.

Radical debridement was performed in all cases, whereas only 3 patients needed a reinforcement of the chest wall with synthetic mesh to stabilize an acute mechanical instability.

Selection of the flap was adjusted to the critical condition of the patients. Wherever possible, the TFL flap was preferred inasmuch as it provides a large area of vacularized fascia in combination with a large reliable skin flap that

\section{TABLE 2. List of complications}

\begin{tabular}{lc}
\hline \multicolumn{1}{c}{ Complications } & No. \\
\hline Prolonged wound healing & 7 \\
Wound infection & 4 \\
Partial flap necrosis & 3 \\
Donor site revision & 3 \\
Arterial thrombosis & 2 \\
Venous thrombosis & 2 \\
\hline
\end{tabular}

allows an effective 2-layer closure of the defect. The included fascia is strong enough to preserve respiratory function in many defects. In addition, the flap can be harvested very fast, the donor site is negligible and can usually be closed primarily, and flap harvest does not influence intraabdominal pressure with a decrease of pulmonary compliance, as in the vertical rectus myocutaneuos flap. ${ }^{9,12,13}$

The most frequently selected recipient vessels for free flap reconstruction in the sternal region are the internal thoracic vessels and the thoracodorsal vessels, but all patients included in this review lacked these recipient vessels. Our previous work has shown that the use of AV loops allows the safe performance of anastomoses outside the zone of infection/injury or in cases in which adequate recipient vessels are lacking. ${ }^{14-17}$

Therefore, the concept of CTA loop was developed to create neovessels at the recipient site and has proven to be a superb tool in our department. ${ }^{18}$ The conventional solution for our subgroup of patients would have been selection of appropriate recipient vessels in the neck, including branches of the external carotid artery, the internal jugular vein, and the external jugular vein, and to perform conventional interpositional vein grafts. Whereas detection of a vein is relatively easy, the location of an appropriate artery may be difficult. ${ }^{19}$ This prompted us to take a closer look at the thoracoacromial/cephalic system.

The thoracoacromial artery arises as a branch off of the axillary artery, and it divides into 4 branches. ${ }^{20}$ It can be

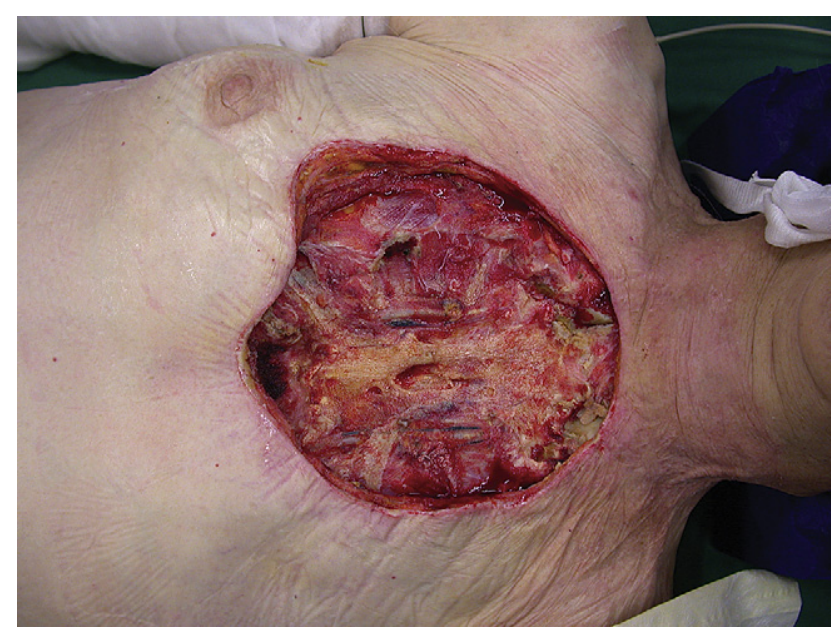

FIGURE 3. A typical chest wall defect (intraoperative photography). 


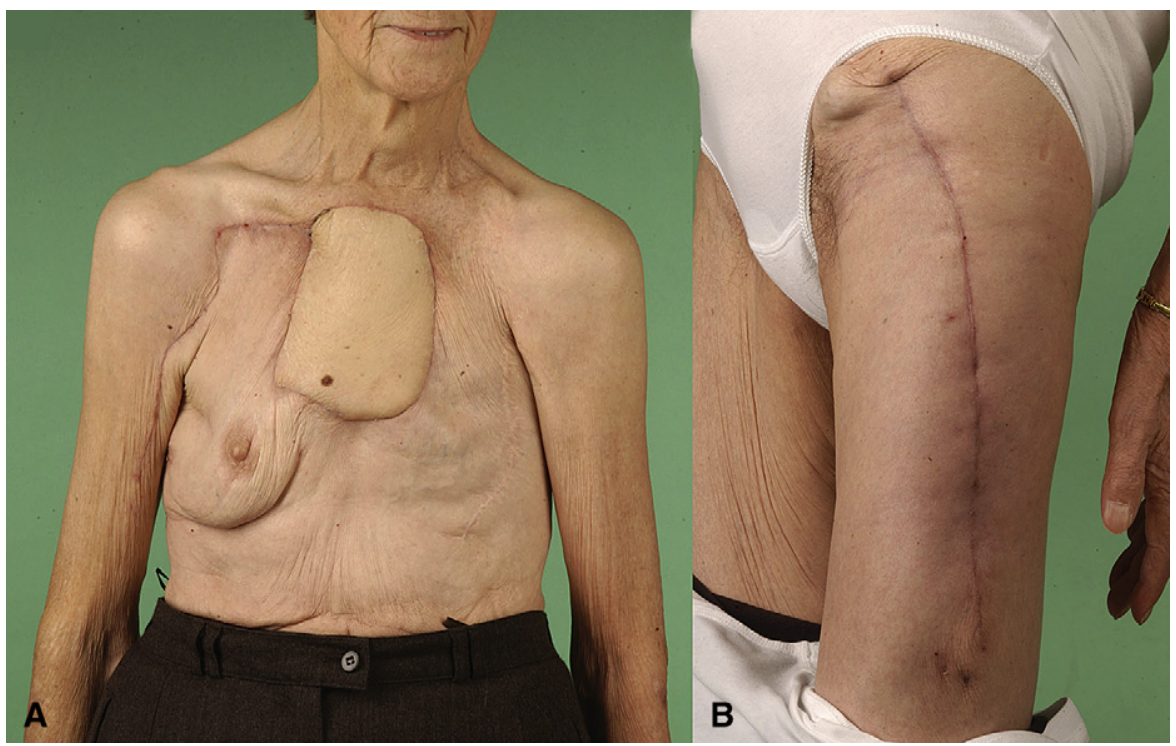

FIGURE 4. Follow-up photographs of an 81-year-old patient showing the recipient site (A) and the donor site (B)

found reliably on the undersurface of the pectoralis major muscle. $^{21-24}$ Even in cases in which a local pectoralis major flap has already been used, dissection of the thoracoacromial vessels was uneventful because the pectoral branch of the thoracoacromial artery, as nutrient blood supply for the pectoralis major flap, runs more distally. The cephalic vein is located in the deltopectoral groove between the pectoralis major and deltoid muscles. It descends along the lateral border of the biceps brachii and passes distally between the brachoradialis and the biceps muscle. It is easily and quickly harvested through an incision along the deltopectoral groove, and distal dissection to the mid biceps provides enough length to transpose it to the central chest wall. The cephalic vein provides the surgeon with a high-flow system that is relatively resistant to stasis and thrombosis. Care must be taken owing to its long subcutaneous route, with the risk of kinking and compression at the level of the clavicle. ${ }^{20,25}$

The thoracoacromial and cephalic vessels were available in all patients, despite the previous use of pectoralis major flaps. Mean operation time was 6.8 hours, and it can be kept short by working in 2 teams, inasmuch as the flap is harvested simultaneously with the creation of the AV loop. The indications and comorbidity of patients who require sternectomy and reconstruction have changed over time, with a subsequent change of the patient population having sternal wound complications. This could be demonstrated by the ASA classification of our patients. The validity of the concept could also be shown with the analysis of perioperative mortality and time of ventilatory support. Only 8 patients required prolonged ventilation. The 30-day mortality of our patients who underwent debridement and reconstruction with CTA loop was $13.7 \%$.
A reduced life expectancy in these patients with multiple morbidities should not alter the reconstructive strategy, because improved quality of life can make the remaining life span truly meaningful. Our data show that the concept has proven to be suitable for a small selected group of highrisk patients.

\section{CONCLUSIONS}

The high success rate of free tissue transfer for chest wall defects has resulted in its increased expansion to a wider patient population that was previously considered unsuitable, including the aged and critically ill. Such patients may present unique challenges in terms of the availability of recipient vessels owing to such factors as arterial occlusive diseases, diabetes, previous operations, or previous use of recipient vessels for other purposes as in cardiac or oncologic surgery. Although this is a minority patient group, the reconstructive surgeon should be equipped to handle such vessel-depleted patients by having a variety of options. The AV loop technique represents a versatile addition to the armamentarium for difficult chest wall reconstructions.

We thank Mrs. Claudia Scheffzük for creating the drawings of the intraoperative situs.

\section{References}

1. Arnold PG, Pairolero PC. Chest-wall reconstruction: an account of 500 consecutive patients. Plast Reconstr Surg. 1996;98:804-10.

2. Losken A, Thourani VH, Carlson GW, Jones GE, Culbertson JH, Miller JI, et al. A reconstructive algorithm for plastic surgery following extensive chest wall resection. Br J Plast Surg. 2004;57:295-302.

3. Chang RR, Mehrara BJ, Hu QY, Disa JJ, Cordeiro PG. Reconstruction of complex oncologic chest wall defects: a 10-year experience. Ann Plast Surg. 2004; 52:471-9; discussion 9. 
4. Mansour KA, Thourani VH, Losken A, Reeves JG, Miller JI Jr, Carlson GW, et al. Chest wall resections and reconstruction: a 25-year experience. Ann Thorac Surg. 2002;73:1720-5; discussion 1725-6.

5. Skoracki RJ, Chang DW. Reconstruction of the chestwall and thorax. $J$ Surg Oncol. 2006;94:455-65.

6. Shrager JB, Wain JC, Wright CD, Donahue DM, Vlahakes GJ, Moncure AC, et al. Omentum is highly effective in the management of complex cardiothoracic surgical problems. J Thorac Cardiovasc Surg. 2003;125:526-32.

7. Walsh GL, Davis BM, Swisher SG, Vaporciyan AA, Smythe WR, WillisMerriman K, et al. A single-institutional, multidisciplinary approach to primary sarcomas involving the chest wall requiring full-thickness resections. J Thorac Cardiovasc Surg. 2001;121:48-60.

8. Cordeiro PG, Santamaria E, Hidalgo D. The role of microsurgery in reconstruction of oncologic chest wall defects. Plast Reconstr Surg. 2001;108:1924-30.

9. Tukiainen E, Popov P, Asko-Seljavaara S. Microvascular reconstructions of fullthickness oncological chest wall defects. Ann Surg. 2003;238:794-801; discussion 801-2.

10. Wettstein R, Erni D, Berdat P, Rothenfluh D, Banic A. Radical sternectomy and primary musculocutaneous flap reconstruction to control sternal osteitis. J Thorac Cardiovasc Surg. 2002;123:1185-90.

11. Deschamps C, Tirnaksiz BM, Darbandi R, Trastek VF, Allen MS, Miller DL, et al. Early and long-term results of prosthetic chest wall reconstruction. J Thorac Cardiovasc Surg. 1999;117:588-91; discussion 91-2.

12. Heitmann C, Pelzer M, Menke H, Germann G. The free musculocutaneous tensor fascia lata flap as a backup procedure in tumor surgery. Ann Plast Surg. 2000;45: 399-404.

13. Penington AJ, Theile DR, MacLeod AM, Morrison WA. Free tensor fasciae latae flap reconstruction of defects of the chest and abdominal wall: selection of recipient vessels. Scand J Plast Reconstr Surg Hand Surg. 1996;30:299-305.
14. Freedman AM, Meland NB. Arteriovenous shunts in free vascularized tissue transfer for extremity reconstruction. Ann Plast Surg. 1989;23:123-8.

15. Grenga TE, Yetman RJ. Temporary arteriovenous shunt prior to free myoosseous flap transfer. Microsurgery. 1987;8:2-4.

16. Hallock GG. The interposition arteriovenous loop revisited. J Reconstr Microsurg. 1988;4:155-9.

17. Threlfall GN, Little JM, Cummine J. Free flap transfer-preliminary establishment of an arteriovenous fistula: a case report. Aust N Z J Surg. 1982;52:182-4.

18. Engel H, Pelzer M, Sauerbier M, Germann G, Heitmann C. An innovative treatment concept for free flap reconstruction of complex central chest wall defects-the cephalic-thoraco-acromial (CTA) loop. Microsurgery. 2007;27: 481-6.

19. Yazar S. Selection of recipient vessels in microsurgical free tissue reconstruction of head and neck defects. Microsurgery. 2007;27:588-94.

20. Jacobson AS, Eloy JA, Park E, Roman B, Genden EM. Vessel-depleted neck: techniques for achieving microvascular reconstruction. Head Neck. 2008;30: 201-7.

21. Freeman JL, Walker EP, Wilson JS, Shaw HJ. The vascular anatomy of the pectoralis major myocutaneous flap. Br J Plast Surg. 1981;34:3-10.

22. Kompatscher P, Manestar M, Schuster A, Lang A, Beer GM. The thoracoacromial vessels as recipient vessels in microsurgery and supermicrosurgery: an anatomical and sonographic study. Plast Reconstr Surg. 2005;115:77-83.

23. Moloy PJ, Gonzales FE. Vascular anatomy of the pectoralis major myocutaneous flap. Arch Otolaryngol Head Neck Surg. 1986;112:66-9.

24. Reid CD, Taylor GI. The vascular territory of the acromiothoracic axis. Br J Plast Surg. 1984;37:194-212.

25. Casey WJ 3rd, Rebecca AM, Smith AA, Craft RO, Buchel EW. The cephalic and external jugular veins: important alternative recipient vessels in left-sided microvascular breast reconstruction. Microsurgery. 2007;27:465-9. 